The influence of social context on the perception of assistive technology: Using a semantic differential scale to compare young adults' views from the United Kingdom and Pakistan

Salman Asghar ${ }^{a *}$, George Edward Torrens ${ }^{\mathrm{b}}$, Hassan Iftikhar ${ }^{\mathrm{c}}$, Ruth Welsh ${ }^{\mathrm{d}}$ and Robert Harland

${ }^{a}$ Department of Product \& Industrial Design, University of Engineering \& Technology,

Lahore, Pakistan

${ }^{b, d}$ Loughborough Design School, Loughborough University, Loughborough, Leicestershire, United Kingdom LE11 $3 T U$

'School of Design, The Hong Kong Polytechnic University, Hung Hom, Hong Kong

${ }^{e}$ School of the Arts English and Drama, Loughborough University, Loughborough, Leicestershire, United Kingdom LE11 $3 T U$

*corresponding author

Email: $\underline{\text {.asghar@lboro.ac.uk }}$ 


\section{IMPLICATIONS FOR REHABILITATION}

Assistive Technology (AT) product designers, academics, professionals and stakeholders need to be aware of challenges which are originated from one's socio-cultural environment. AT products convey certain meanings, semantics, which are interpreted by the society and are subjective to a specific cultural setting.

- For the effective communication of meanings and values an AT product relies on the visual clues and design features embedded within the design. However, there have been a limited number of studies reviewing this aspect of product semantics.

- The survey and associated testing has highlighted the differences in cultural perception towards AT products and demonstrated the importance of effectively designing the semantic attributes of an AT product as well as its function.

- The demonstration of the efficacy of methods within the study for exploring the interpretation of semantic attributes of AT products will help designers and developers better understand the perceptions of individual cultures and societal groups.

- A better understanding of different cultures and societies will enable designers and clinicians who specify AT products to reduce AT product abandonment; and, the associated stigma around disability. 


\title{
The influence of social context on the perception of assistive technology: Using a semantic differential scale to compare young adults' views from the United Kingdom and Pakistan
}

\begin{abstract}
A Society's view of disability may influence the perception and use of Assistive Technology (AT) products. Semantic cues or cultural coding provide the viewer with a series of visual stimuli to be given or ascribed meaning. Previous research has shown cognitive approaches to visual perception and assignment of meaning vary between diverse cultures. This study reviews the influence of contextual settings on perception, to provide the basis for a debate on the societal perception of communicative content (semantic /meaning) of an AT product; and, the relevance of different cultural cognitive styles. The paper explores, from a cultural viewpoint, the overall understanding of disability internationally. A Semantic Differential (SD) scale was used to obtain views on the image of an attendant wheelchair from nine hundred and ninetyone (991) young adults from the United Kingdom (UK) and Pakistan (PAK), reflecting the individualist and collectivist societies, respectively. This survey follows a previous paper-based study using the same image and protocol. Comparing the two surveys, a consensus of views from the two groups was achieved. The responses from the UK group were skewed towards a negative view of disability compared to the Pakistan group. This inferred greater social stigma associated with this AT product in the UK. The combined findings from both surveys provide insights into societal perception of AT products and disability. Areas for future research are suggested, including what visual components of an AT product (graphemes) appear to be associated with positive or negative responses for collectivist and individual societal groups.
\end{abstract}

Keywords: Assistive Technology (AT) product, Cognitive Styles, Culture, Product Semantic, Society, Stigma, 


\section{Introduction: Disability, society and Assistive Technology (AT) product}

The international Assistive Technology (AT) market is worth around $\$ 42,360.0$ million (approximately $£ 35,165.0$ million) [1]. The perception of AT products from the viewpoint of Western and Asian societies has not been previously addressed. This study will focus on eliciting opinions about AT products and disability from individuals who live within different societal constructs. Opinions will be elicited through a visualisation of a generic manual attendant wheelchair; providing insights that may lead to a reframing of society's perceptions of disability.

According to the World Health Organization (WHO) report, ten (10) percent (one billion people) of the world population has some sort of disability [2]. The increase in prevalence of disability and number of elderly people, resulted in the growing demand of associated products for disabled people or formally termed as Assistive Technology (AT) products $[1,3-10]$. The frequently cited and internationally accepted definition for the AT products is "any item, piece of equipment, or product system, whether acquired commercially off the shelf, modified, or customized, that is used to increase, maintain, or improve functional capabilities of individuals with disabilities" [11,p.17]. The definition encompasses a broad range of products, earmarked for the specific needs of disabled people and subsequently provides the user's with an opportunity to participate in their society $[12,13]$. The use of function-focused AT products as defined occurs within a regional and colloquial sociocultural environment [12].

Despite the increase in demand and importance of such devices, AT products are abandoned (non-use) at high rates [12-16]. The societal perception of disability (stigma or negativity) and meanings attributed to AT products, are considered to be potential factors affecting the use or non-use of those devices $[12,13,16]$. Commentators in the field of disability studies emphasise of the significance of social context(s) within which AT products 
are used. However, studies involving assistive technologies appear to focus on functionality and usability of AT products [12]. Less importance appears to be given to the communicative (semantic/meaning) content of AT products $[3,10,12,13,17]$.

Ripat and Woodgate state that the notion of culture - the beliefs, values, meanings and actions that shape the lives of a collective of people, influencing the ways people think, live and act -- may be seen as a primary determinant when considering the communication of meanings through an artefact. [18,p.88] Based on the distinct characteristics of their respective societal structure, experts from the field of cross-cultural psychology have reported differences between Asian (collectivist) and Western (individualist) societies [19-22]. Meanwhile, there exists a dearth of research regarding the understanding of disability from cultural perspective or studies relating to the semantics, meanings, attributed to the AT product $[10,13,18,23]$.

This study reviews the perceived influence of contextual (sociocultural) settings that matched against the results of a recent study by the authors [10]; providing a basis for discussion about the differences in societal perceptions of the semantics/meanings of an AT product. The earlier survey suggested that the internationalist environment of a University acted as a mediating agent, delivering normalised views and doctrines from two student populations in different countries [10]. This study extended the findings of the earlier survey through collecting the responses of young adults from a general population of individualist (United Kingdom) and collectivist (Pakistan) societies. The hypothesis was that young adults from diverse cultures, would assign different meanings and values to an image of a generic wheelchair and its associated envisaged user. Another objective of the study was to check the degree of similarities and/or differences among the responses of students and non-students (general) population of both cultural groups. To meet those intended aims and objectives, a Semantic Differential (SD) scale using three factorial categories -- evaluation, potency and 
activity -- was applied. The efficacy and relevance of SD scale in relation to the hypothesis are discussed in the conclusion. The term 'ascribed' indicates the meaning, credit, and value attributed to an artefact by the individual (perceiver) within their respective sociocultural environment. According to Krippendorff [24], product semantics can be defined as "a vocabulary and methodology for designing artefacts in view of the meanings they could acquire for their users and the communities of their stakeholders" [24,p.03]. Terminologies and definitions associated with disability are described, using an international perspective, to provide a broader context within which the findings of the study may be viewed.

\section{Culture and disability}

Disability can be represented as a culture [25,p.35]. However, there is a complex interplay between culture and disability. As the individual's social values, doctrines, beliefs and norms are imperative to define each concept (disability or culture) $[18,25,26]$. From an international perspective, the term 'disability' could have different meanings [25]. Therefore, the associated meanings of disability could differs substantially among diverse cultures [18,27]. Of just Western societies, consensus on an agreed upon definition of disability has been contested rather based upon two dichotomous paradigms [18]. For instance, the orthodox medical model locates the 'problem' with the individual (personal tragedy), while rejecting any assumption that indicates the role of society in creating disability [11,28-30]. In contradiction, the social model takes disability out of the individual, into the societal structure, where disability may be considered as 'social oppression' [31,32]. The contradiction regarding the source (individual versus society) demonstrates how those different models can lead to diverse approaches to address the subject matter (disability) [18]. 


\section{Cultural difference: societal and cognitive}

An approach to understand disability is through the cultural sphere of values, meanings and doctrines within one's particular sociocultural context [33]. The theory of social constructionism can be used to explore the socially constructed meanings of the disability with a focus on particular cultural context $[34,35]$. The fundamental assumption of social constructionism provides a critical stance of an individual's ways of understanding the world, which is often taken-for-granted [38]. Individuals develop an understanding of the phenomenon i.e. disability, through their sociocultural coding. Subsequently, the opinion about disability is based on specific societal norms, values and meanings associated with the concept $[18,34,35]$. Consequently, investigating the societal structure and individual's way of thinking (cognition) could provide insightful information into meaning(s) of disability within ones cultural context $[18,34]$. Moreover, socially accepted meanings of disability among diverse cultures might lead to recognise an agreed explanation of disability, and its associated AT products $[13,18,34,36]$.

Recurrent cultural dimensions from the Hofstede model, could be used to investigate the extensive topic of culture. In that model, individualism and collectivism aspects indicating Western and Asian cultures, respectively, were well-highlighted by Geert Hofstede [19]. Both societies have marked differences in the formation of their societal structures. The collectivist societies place priority to live in complex networks (groups), shared value system, interdependent self-construal and thus, demonstrate group harmony [37-42]. Conversely, members from individualist societies put more value to independent self-construal, lesscomplex relationships with other members, self-related goals and personal autonomy[38-44]. The cultural differences become more evident for emotional assessment of other members of society [41]. Those variations in social values between collectivist and individualist cultures, 
appears to lead to the development of two distinct thinking (cognitive) approaches (holistic and analytical).

Recently, interventions investigating 'the cultural influence on the way individual perceive the visual world' has been increased. Holistic and analytical systems of cognition can be outlined as follows:

Analytical cognition encompasses;

- A detachment of the object from its context.

- A tendency to focus on attributes of the object in order to assign it to categories.

- A preference for using rules about the categories to explain and predict the object's behaviour.

- Inferences rest in part on decontextualization of structure from content, use of formal logic, and avoidance of contradiction.

Holistic cognition invovles;

- An orientation to the context or field as a whole, including attention to relationships between a focal object and the field.

- A preference for explaining and predicting events on the basis of such relationships.

- Experience-based knowledge rather than abstract logic and are dialectical.

Emphasis on change, a recognition of contradiction and the need for multiple perspectives. [40,p.19]

Until recently, there has been no empirical evidence that addresses how those cultural cognitive differences are relevant within the domain of disability and associated AT product. Meanwhile, authorities and commentators in the field have highlighted that researchers need to investigate intersection between culture, AT product and their ascribed meanings. $[13,18,23,37]$. 


\section{Product Semantic and product-related stigma}

An artefact performs various types of functions [45]. Once the practical needs have been satisfied, the focus then shift towards the communication (intangible) function of artefacts [46]. The 'offenbach theory of product language' has regarded semantics as an important communicative function of an artefact. [46-48]. Within a sociological perspective, the social constructivism advocates that product semantic(s), the meaning(s), are constructed within a particular sociocultural environment at a given time [34,35,49]. Giacomin [49] indicated that sociologists have shown the semantic(s), the meaning(s), ascribed to a product are relative to the particular culture. Similarly, Watson [50] claimed that the semantics given to an artefact are culturally defined and vary substantially, when considered through diverse cultural settings.

Considering disability and semantics of AT product, stigma has been argued as an important social phenomenon. Stigma is a term used to describe a strong feeling of disapproval about something within society and of which an individual is made to feel ashamed [10]. The AT products inevitably receives the stigma causing the social rejection of those products [51]. Through the process of product-related stigma, an individual unimpeded with the stigma might induce the stigmatic reaction because of the negativity associated with the AT product(s) $[16,51]$. From this view, the meanings and social significance of the AT products could be considered as an important predictor that defines product-related stigma $[51,52]$. The stigma and subsequent meanings assigned to AT are defined within a specific sociocultural setting. From this perspective, cultural factors regarded as persuading factor in the creation of meanings ascribed to AT products $[18,51]$.

In an attempt to answer; 'how cultural differences (societal and cognitive) influence on the semantics ascribed to AT product image?', this research extended the findings of earlier 
survey [10]. This study aimed to test an assertion that cultural differences between value system of collectivist and individualist societies may results in difference of societal views towards semantics given to the manual wheelchair. To address the intended objective, this survey followed a previous smaller study using the same image and protocol. An online questionnaire in conjunction with Semantic Differential (SD) scale was used to probe the semantic content of the product, within the context of the UK (Leicestershire) and Pakistan (Punjab).

\section{Method}

The online questionnaire was reviewed by the Ethics Approvals (Human Participants) SubCommittee of Loughborough University, who granted the ethical approval to conduct the study. Ethical approval was obtained for the protocol via the Institutional ethics committee. [53].

For both (UK and Pakistan) cases, respondents were provided with an Internet link that took the respondents to the online questionnaire, which began with an integrated participants information sheet and consent form. By continuing through to the survey, participants were made aware that they were automatically consenting to take part in the study.

The sampling approach for this study entailed a probability sampling because the inclusion of young people forms a sub group or a cluster (young people) of the population. The authors employed Simple Random Sampling (SRS) coupled with cluster samples for recruiting young adults from both cultural groups. These sampling approaches were employed to gather data from the effective respondents as well as to avoid the research from the possibility of biased sampling. 
Young adult participants were intentionally selected for this online survey, to match the age range from the earlier University-based sample group. Social media websites were used to publicise the survey to the relevant participants of both groups.

The online version of the questionnaire was refined from the previous paper-based version to improve participants understating of questions. [10] The order and logic of the questions were reviewed. The terminology and phrasing used in each question were considered against the results from the whole study where inconclusive answers were highlighted. This was to double-check the results were not due to a lack of clarity of question presented. Each question was considered in the context of the sequence presented, alongside post-processed statistical outcomes.

An online questionnaire was considered useful as the researchers wanted to obtain a large number of responses to gain a consensus [54,p.226]. In such a case, this method was preferred over a self-administrated, postal or e-mail questionnaire [54-56]. The Semantic Differential (SD) scale measured the participant's perception of semantics ascribed to visual representation of an attendant wheelchair and its envisaged user.

A number of online surveys were reviewed including: Survey Monkey [57]; Google Docs [58]; Typeform [59]; and, BOS (British Online Survey) [60]. The websites provide services to develop a customised online questionnaire. However, in order to develop the same Semantic Differential (SD) scale applied in the first study in an online questionnaire the BOS website was considered the most suitable. This was due to the flexibility of individual question set-up/design and an option to adjust the image resolution when viewed on a range of peripheries, such as Smart phone displays, Personal Awareness Devices (PADs) i.e. IPAD, touch screen, as well as on conventional computer screens. 
The questionnaire was organized into three sections that: 1) characterized the socioeconomic profile of the participant; 2) a semantic differentiation scale to characterize their opinions about a given AT product (a wheelchair); and, 3) their opinions about those who might use it.

To incorporate non-student participants in the study, Question four (4) was changed to 'What is your current employment status?'. Additionally, alterations were made to the first study SD scale that defined the attributes of an envisaged user of the manual wheelchair. Previously, this scale had sixteen pairs of adjectives that were grouped according to their respective factorial categories (Evaluation/Capability, Potency/Social value). From the earlier study, participants noted that some pairs of the adjectives (six) represent similar attributes or were inaccurate, when applied to the perceived end user. These were removed from the SD scale of this study, reducing the number from sixteen (16) to ten (10). The second section, 'Product Semantics', comprises of sixteen (16) pairs of antonymous adjectives, defining the semantic attributes of the AT product. The SD scale was followed by the semantic persona profile modified from the first study. Also, it was noted by the participants in the first study that they did not understand the association between the numbers (1-7) and the pairs of adjectives. This scale was modified to describe the precise location of the numbers on the scale. For instance, previously the numbers were used in isolation from ' 1 ' to '7', which were replaced by 'Strongly Aligned 1' and 'Strongly Aligned 7', respectively. Similarly, the position of number '4' was mentioned as 'Neutral 4'. Figure 01 shows how those alterations were applied.

\section{[Figure 01 here]}

The third section of the online questionnaire reviewed the participant's own perception as a user of the wheelchair by means of a Likert scale. These questions were to 
provide insights into the participant's views and feelings about those who might use the AT product (manual wheelchair) in different social settings such as; with family, office or public place. Additionally, this section reviewed, if there was a bias of opinions due to previous experience of interacting with a manual wheelchair. The final question identifies through which medium respondents had completed the online survey. This was intended to provide information to analyse the visual aspects (image and font size, instructions provided, location of question on the page) of the questionnaire.

To effectively check and compare the results of this study with the findings of the first study, no alterations were made to define the semantic attributes of the AT product. Consequently, the same, sixteen (16) pairs of adjectives with their corresponding factorial categories (evaluation/function, potency/social value, activity/usability), were integrated in the SD scale. The same visualisation of an AT product (generic manual wheelchair) was used in the online version of the questionnaire. However, the resolution of the visualisation was adjusted to match the appropriate fidelity (resolution) of the screen, on which the survey would be displayed. For both SD scales, pairs of adjectives with their corresponding positive or negative dimension were presented in an arbitrary grouping. This was to reduce the potential bias associated with the placement of adjectives (positive and opposing adjective on the either side of scale).

\section{Post-processing}

All responses were gathered and screened; inaccurately completed or incomplete questionnaires being excluded. Inaccuracies were considered for responses with two or more missing SD scale answers. Filters were applied to restrict the participants of other nationalities to take part in the study. 
Post-processing of the questionnaire data was completed to identify the nature of similarities and differences in the response of both groups. As this study employed probability sampling for data collection, the post-processing of data was done using appropriate statistical analysis.

To acquire valid outcomes (in terms of positivity/negativity), the scale was reorganised, and the randomised sequence of adjectives was replaced by engaging positive and negative values on either side. From this approach, the response for each pair of adjectives varied between 'strongly aligned 1' (negative, does not indicating the user well) and 'strongly aligned 7' (positive, indicating the user well). Whereas, the middle value ' 4 ' defines the neutral position demonstrating that the respondents do not want to express their opinion for the corresponding pair of adjectives.

From the first study, some concerns where highlighted about treating the SD scale data either interval or ordinal. The selection of treating the SD scale data as ordinal or interval was critical to select the subsequent appropriate statistical test (parametric or nonparametric). Literature was reviewed to ensure the optimal statistical processing was used. Based on evidences from literature, the SD scale data was treated as interval $[56,61,62]$. Additionally, the related explorations further supported the parallel administrability of such an approach [17,63-69].

As the responses of participants from the UK may not necessarily be linked with or depend on the answer of participants from the other group and vice versa; the responses of each group can be considered as 'independent' of the other. Therefore, considering the assumption of independent sample groups, effective statistical tests for interval nature of data are performed to obtain valid outcomes. 
Shapiro-Wilk test (normality assumption) [70] and independent sample t-test (comparison) [70] were performed. The reliability or significance value (p) from the application of a Shapiro-Wilk test exceeding $0.05(\mathrm{p}>0.05)$ would indicate a normal distribution of the data. Although, for larger samples normality distribution would not overtly influences the findings of the study [70]. However, in order to obtain reliable outcome from questionnaire data, the normality of responses was checked. Following the results of ShapiroWilk test (not normality distribution) but having the larger number of responses, the 'Mean' (M) values were considered to perform parametric tests. To investigate the nature of similarities and differences, independent sample t-test compared $\mathrm{M}$ values of each pair of adjectives of one group to another.

The responses of both cultural groups were compared against each other, using an independent sample t-test. The statistical 'independent t-test' was performed on all variables (pairs of adjectives) used in the SD scale. The independent sample t-test compared means (M) of both groups. The statistical outcomes were regarded as significant, when the reliability or significance value $(p)$ was less than $0.05(p<0.05)$. The independent $t$-test assumes the variance (number of participants) of two groups to be equal. The assessment about the homogeneity of variance was made from t-test for Equality of Means. Through t-test, the results of Levene's Test for equality were also derived and checked against the former. This comparison was performed to establish confidence in the results drawn from the questionnaire data.

Microsoft Excel software [71] was used to compile the demographic information as well as to obtain primary descriptive statistical data. For all types of statistical test, the questionnaire data was processed by means of Statistical Package for the Social Scientist (SPSS) software [72]. Finally, the graphical representation of the results was made by using either MS Excel and/or Adobe Illustrator [73] computer programs. 


\section{Results:}

The detailed dataset associated with this study can be accessed through Figshare [74]. This study aimed to collect, as far as possible, of six hundred (600) responses from each group. Therefore, the survey was distributed among the relevant participants in the UK and Pakistan, accordingly. With a response rate ${ }^{1}$ of ninety (90\%) percent, total one thousand and eightyfive (1085) responses were collected. However, applying the exclusion criteria through the online filters on BOS, reduced the number of responses to 991 ( $83 \%$ of expected response rate) to be included for analysis. In total, 427 (43.1\%) female participated in the study which was less than the total numbers of male $564(56.9 \%)$ participants.

Socio-demographic characteristics (age, gender, profession and culture) were broken down by the groups presented in the following Table 01 . With regards to distribution of participants based on the gender, majority of the respondents from the UK were male (244, $55 \%)$ in comparison to female $(200,45 \%)$. Similarly, there were more male participants in the Pakistan group $(320,58.5 \%)$ compare to female $(227,41.5 \%)$. Participants from both cultures belonged to the same age group (18-30). The following Table (01) presents a summary of the demographic profile of participants from both societal groups.

[Table 01. here]

As a part of participants demographic information, all respondents from the UK were from a specific part of the England (Leicestershire); the Pakistani respondents were from the largest city of Punjab (Lahore). $72.1 \%$ of participants from the UK responded to "practice a religion". $95.2 \%$ of the respondents from Pakistan marked 'Islam' as their practicing religion.

\footnotetext{
${ }^{1}$ The response rate refers to the percentage of sample that does, in fact, agree to participate in the study [55]. The response rate can be computed by using the following recipe: Response Rate $=($ Responses Returned $) /($ Surveys Sent Out $) * 100$
} 
In addition to demographic profile, all participants were noted not to have any physical impairment or disability. Therefore, no respondent in this study was reported as a permanent wheelchair user. Some participants indicated that they had previous personal experience of using wheelchair (5.4\% in the UK and 7.5\% in the Pakistan). $48.6 \%$ participants from the Pakistan and 18\% from the UK indicated that they had helped a wheelchair user. $14.4 \%$ from the UK and $23.6 \%$ from Pakistan indicated that they had a wheelchair user as a friend or family relation. See Table 02 .

[Table 02. here]

The first SD scale was utilized to check the participants opinion towards the envisaged user of the attendant wheelchair by employing ten (10) pairs of adjectives. To interpret the response data, descriptive statistics were computed for each pair of adjectives, from questionnaire data of both cultures and presented in the Table 03 .

[Table 03. here]

In the responses of both groups, the peak mean (M) value was noted for two pairs of adjectives, labelled as old-young and able-disabled. For the adjectives old-young, mean values were noted as $\mathrm{M}=2.71(\mathrm{sd}=1.10), \mathrm{M}=3.04(\mathrm{sd}=1.92)$ for participants from the $\mathrm{UK}$ and Pakistan, respectively. The same numerals for adjective able-disabled were remained at '5.54' for the UK participants and '4.67' in the responses from the Pakistan. Following this, pairs of adjectives immobile-mobile with $\mathrm{M}=3.17$ (UK), $\mathrm{M}=3.65$ (PAK) and independentdependent $\mathrm{M}=4.94$ (UK) and $\mathrm{M}=4.59$ (PAK) indicate the user's attribute toward the immobile and dependent categories.

The significance (p) value provides the comparative analysis to measure similarities and/or differences of questionnaire data from both cultures. Seven cases out of ten pairs of 
adjectives, were found to have statistical difference in the responses of both groups. Below Table (04) shows the resultant $p$-values for all pairs of adjectives, indicating the presence of statistical difference $($ where $\mathrm{p}<0.05)$. For example, the results of independent sample t-test shows that $\mathrm{M}$ values for adjective old_young does differ between the responses of the UK $(\mathrm{M}=2.71, \mathrm{sd}=1.103, \mathrm{n}=444)$ and Pakistan $(\mathrm{M}=3.04, \mathrm{sd}=1.922, \mathrm{n}=547)$ having 0.002 level of significance $(t=-3.182$, degree of freedom $(d f)=989, p<0.000$, with confidence interval $(\mathrm{cf})$ of $95 \%$ for mean difference being $-0.528,-0.125)$. Difference in the means of UK and Pakistan remains at -0.327 .

\section{[Table 04. here]}

The overall findings from the independent sample t-test suggest statistical difference exits between the responses of both cultural groups. On the other hand, the p-value was noted at 0.817 for a pair of adjectives unsociable _ sociable indicating no statistical difference between the groups. Similar response with no statistical difference was noted for pairs of adjectives, incompetent_proficient and happy_unhappy, where p-values were computed as 0.86 and 0.138 , respectively. For those pairs, as shown in Figure (02), responses indicate that groups have similar nature of responses without any or minor variation. The overall findings of t-test were check against the visual representation of $\mathrm{M}$ values of both groups. With greater/lesser degree of variations, the respondents of both cultural groups were found to have similar opinions regarding the envisaged user of the attendant wheelchair for the provided pairs of adjectives. The respondents (UK and Pakistan) perceived an old, disabled, immobile and dependent person as a user of the manual wheelchair.

\section{[Figure 02 here]}

Figure 03 show 'negativity' and 'positivity' associated with the envisaged user of the wheelchair. The overall responses of participants from both cultural groups were skewed 
towards the adjectives indicating the negative attributes of the envisaged user. In responses for two pairs of adjectives not perceived to define the user attributes were incompetentproficient and sociable-unsociable, for which the responses of both groups were marked as close to the neutral position.

[Figure 03 here]

To get clearer information from second SD scale, descriptive statistics (standard deviation (sd), Minimum (Min), Maximum (Max), Mean (M)) were produced (shown in Table 05).

[Table 05. here]

A t-test was performed on all pairs of adjectives (sixteen times for responses of both groups). Notably, for most of the cases (twelve times), the reliability (p) value was noted to be less the significant value (0.05), directing the presence of difference between the responses of both cohorts. The statistical differences were found for the factorial categories defining the functional (such as; compact_bulky, small_large, dynamic_static, light_heavy) as well as the social values (negative_positive, stylish_unstylish, standard_customised, beautiful_disgusting, desirable_undesirable, outdated_modern) of the product. The p-value for pairs of adjectives (effective_ineffective and difficult-to-use_easy-to-use) also indicated statistical difference across the groups. Further interpretation of the questionnaire data revealed the following information (presented in Figure 04):

While, describing the associated results for pairs of adjectives, some labels were used in analysis to specify important values such as; $\mathrm{df}=$ Degree of freedom, $\mathrm{t}=\mathrm{T}$-test value, $\mathrm{p}=$ Significance value, $\mathrm{CI}=$ Confidence of Interval.

Based on the descriptive statistics and p-value of the independent t-test, there was significant difference noted for adjectives (outdated_modern) with $\mathrm{t}=-14.25, \mathrm{df}=988.0$, 
$\mathbf{p}=\mathbf{0 . 0 0 0}(<\mathbf{0 . 0 5})$, and CI of $95 \%$ mean difference being -1.656 and -1.255 in the responses of both groups. Difference in the means of UK and Pakistan remains at -1.45 . The respondents from the UK noted the product to be outdated; the responses from Pakistan group were inclined slightly towards the adjective modern. Likewise, the visual representation of the results shows that participants from both groups perceived the product as drastically different, when apprising the product between outdated and modern. Considering the neutral position (04), the similar fluctuation having contrasting nature of responses was noted for pairs of adjectives including compact_bulky, dynamic_static,negative_positive, beautiful_disgusting, light_heavy.

For some pairs of adjectives, statistically significant difference was noted for both groups. For example, when perceiving the wheelchair between desirable and undesirable, difference was noted having $\mathrm{t}=13.394, \mathrm{df}=988.42, \mathbf{p}=\mathbf{0 . 0 0 0}(<\mathbf{0 . 0 5})$, and $\mathrm{CI}$ of $95 \%$ mean difference being 1.214 and 1.630. Difference in the means of UK and Pakistan remains at 1.422. The participants from the UK perceived the wheelchair to be undesirable with much greater strength compare to the responses from the Pakistan. The Pakistani respondents, on the other hand, reported to have similar opinion but with lesser strength towards the undesirable. Similar pattern of fluctuating response was discovered for other pairs including; small_large, standard_customised and stylish_unstylish.

Although statistical differences were noted for adjectives, further exploration of the graphical representation of data, highlighted the nature of differences. Therefore, the resultant outcomes for some adjectives suggest fluctuation (with greater or lesser degree of variation) of participant's opinion rather that conflicting responses. Following Figure (04) show examples of such responses, where fluctuating (right) and conflicting (left) responses were reported. 
[Figure 04 here]

\section{Comparing Groups Responses}

Referring the Figure 05, most of the adjectives in the factorial group indicating the social (potency) and functional (evaluation) values describe contrasting differences among the responses of both cultures. The p-value (less than 0.05 ) with their corresponding visual representation further affirms those results. Despite of having statistical difference in two cases (effective_ineffective and difficult-to-use_easy-to-use), the pairs indicating the usability aspects were noted to have similar nature of responses between both groups.

Considering all means values (sixteen) from the UK as one group, and the same numeral from Pakistan as another, independent sample t-test was completed, resulting a pvalue $0.569(p>0.05)$. Twelve pairs were found to have statistical differences from which six (06) were noted to have contrasting opinions of participants of both groups. The overall reliability supports that no substantial difference (conflicting) exists between both groups.

[Figure 05 here]

\section{Associated 'Negativity' or 'Positivity'}

Results were extracted from questionnaire data in terms of 'positivity' and 'negativity' as depicted through the pairs of adjectives. Following Figure (06) presents the comparative analysis of responses for all pairs of adjectives. Overall, for majority of adjectives, the feedback of participants from the UK was inclined towards the 'negative' portion of the scale. For the same group, the rapid shift was observed for some pairs of adjectives from 'negative' towards the 'positive' attribution of the product ('desirable_undesirable' towards 'effective_ineffective'). The overall responses for the Pakistan group were skewed slightly from the neutral position, towards the positive section of the scale. Although, for some 
adjectives, responses were tailed in the 'negative' domain of the scale, but this happens just twice ('small_large', 'standard_customised').

[Figure 06 here]

\section{Interpretation based on gender-related biases}

While addressing the user's perspective in an exploration, Lanutti et al. [17] noted difference of perception towards wheelchair based on the gender. The questionnaire data was analysed to check potential variations (if any) based on the gender of participants form both groups. Corresponding to the total number of male $(\mathrm{N}=564)$ and female $(\mathrm{N}=427)$ participants, descriptive statistics were computed.

The results related to the factorial category defining functional attributes of the product, no significant difference was noted between the male and female participants. Fluctuations were noted within responses, when considering social value and meaning of the product. Differences in the adjectives expensive_inexpensive were observed between male and female participants. For the adjectives desirable_undesirable, fluctuations were noted. This occurred for most of the pairs of adjectives within this factorial category (see Figure 07). The category indicating the usability aspect of the product provided no difference or variation between cultural groups. Overall, there was no statistical difference noted based on the gender of respondents.

[Figure 07 here]

\section{Experienced respondents with those having no experience}

The study defines an 'experienced person' who had experience of interacting with wheelchair either as a user or a caregiver. Table (06) below presents the mean (M), and standard deviation (sd) values for adjectives where some differences were noted. 
[Table 06. here]

In results for adjectives related to functional attribution of the product, respondents reported differences, indicating their opposing views. Pairs of adjectives dynamic_static and compact_bulky highlights those differences (presented in Figure 08). The factorial category 'social value', respondents with previous experience reported the product as excluding compared to the responses of participants who consider the product to be including. Respondents having experience of interacting with a wheelchair or user reported a positive perception for most of the pairs of adjectives compared to the other members of this group.

[Figure 08 here]

\section{Comparison of student's responses with general population (Study 1)}

The finding of this study agrees and supports the overall results of the pilot study, for which, no statistical difference was noted between the overall responses of both groups. However, further comparison of two studies, brought up some interesting and overlapping results. The comparison of pairs based on factorial categories suggest that for functional attributes of the product, overall findings of pilot study lines up with the outcomes of this study. For instance, in both studies, the participants from the UK, perceived the wheelchair to be heavy, whereas, the Pakistani respondents suggested the product as light, in both studies. Likewise, similar pattern of participant's opinion was noted for other adjectives in this factorial category (weak_strong, dynamic-static, compact_bulky, small_large). With the exception of one pair of adjectives, similar responses were noted for factorial group demonstrating the social value of the product. This was discovered for pair beautiful_disgusting, where the responses from the Pakistani groups was different, as that of what revealed in the previous survey. Statistically more differences were observed in this study compare to the earlier desk-based survey. Finally, for 'usability' aspect, the results of both studies match with each other. 


\section{Discussion}

The findings support the outcome of the first study. As a non-user (mainstream) members of the society, their opinion may not integrate sociocultural aspects as being observed by the user group. This may be a reason why this study does not match with the outcomes highlighted by Lanutti et al. [20]. Overall, the respondents from the UK group found to express their opinion regarding the subject (wheelchair) more explicitly, compare to the responses of other group, for which, the overall findings were much close to the 'neutral position'. The same was noted by Edward T. Hall [75], who claimed that members of low context (individualist) process information explicitly, where less information is obscured or internalised to express their opinion(s). Whereas, individuals of high context (collectivist) interpret the information from a message implicitly, where most of the information is either in the physical context or internalised in the person.

The results of this study demonstrate that individuals from both groups perceived an old, disabled, dependent, and immobile person as an envisaged user of the product. Although, with substantial statistical difference of groups, this finding (first SD scale) provides an evidence of rationale understanding of participants towards the envisaged user of the attendant wheelchair. Presumably, this justifies the appropriate selection of method (SD scale) and sample population. Meanwhile, this also highlights the overall negativity (social stigma) of mainstream society associated with the disabled person or the individual with impairment(s). Again, those findings were aligned with the outcomes of the pilot survey.

Differences were reported for the semantic attribution(s) of the product (wheelchair) in twelve (12) pairs of adjectives, from which, six (06) were found to have conflicting patterns of responses. Cultural differences might have moderated this pattern; the UK respondents showed higher perceptual tolerance towards 'negativity' associated with the pairs of adjectives in mismatching context compare to their counterpart (Pakistan). Individuals 
from the collectivist (Pakistan) society reported a higher level of product liking (positivity), compare to responses from individualist (UK) society. However, comparing the overall responses of both groups, statistical differences in twelve out of sixteen cases, supported the hypothesis. Importantly, compare to the pilot study, there were relatively larger number of participants in this group. These results show that for young members of society, individuals with previous experience of interacting with AT products, found to have 'positive perception' of AT products, compare to those having no experience.

Another objective of this study was to attempt an investigation of the perception of disability depicted through the Assistive Technology (AT) product and associated social stigma form the viewpoint of diverse cultures. This goes beyond the functional characteristics of the AT product towards visual language (semantics) of these artefacts, which has been argued as a vital domain towards socially acceptable design $[18,76,77]$. Product semantics has been explored widely from the perspective of mainstream product through various pancultural studies [78-81]. Until recently, there has been no reliable evidence that reviews the semantic attribution of AT products through the diverse cultural perspective. According to Vaes [51], an industrial designer holds the responsibility to explore opportunities to manipulate the societal perception, through the visual language of an AT product. The inspection of societal perception towards the visual domain (product semantics) of AT product potentially inform the AT product designer; who can then conceptualise and develop products by incorporating the needs, not only of users, but also the larger group of members that surround users [18].

A strength of this study was its exploratory design using a mixed methods approach and a larger number of young people from both groups. The comparison of findings with previous (student group) survey confirms the consistency of results and validates the relevance of method selected for this study. The study was not intended to represent an entire 
population of both groups but provide views of young adult's perception within the context of the UK and Pakistan.

The study had limitations. Both cultures (Pakistan and UK) have a number of regions that may have a sub-culture, which could possibility influence the results if a sample was obtained from them. The limited age range (18-30 years old) restrict the generalisability of results. Future studies might wish to incorporate clusters of the individuals' representing different age groups from diverse cultures. Employing more rigorous process (Principal Component Analysis, PCA) for selection of pairs of adjectives could be advantageous for future studies $[56,61,69,82-86]$. This study does not address the relationship of religious practices and cognitive styles of perception for both groups. Further studies need to be undertaken that account for these variables. Finally, as noted in the review of literature that members of collectivist and individualist societies have diverse viewing behaviour. Therefore, further studies are underway, inspecting which visual components of an AT product (graphemes) appear to be associated with positive or negative responses for collectivist and individual societal groups.

\section{Conclusion}

This study was intended to compare the perceptions towards AT products and their users of two groups of young adults (Pakistan and UK) from a general population, compared to an initial study involving only University students.

The Semantic Differential (SD) scale found participants from both groups of the general population had a similar pattern of thinking towards the envisaged user; and, perceived the user as an old, dependent, immobile and disabled person. Participants from both cultural groups evaluated the user with adjectives placed on the negative segment of scale. This indicated the overall negativity or social stigmatising of a disabled person. 
Statistical and contrasting differences in responses from both groups were noted when perceiving the AT product. Adjectives chosen included outdated_modern, compact_bulky, dynamic_static, negative_positive, beautiful_disgusting, light_heavy. Despite of having statistical difference in most (twelve) of the pairs, the graphical representation of results suggested fluctuations between the responses of both groups. This was consistent with the findings of first study conducted with the student population. However, it was interesting to note that the participants from the UK group perceived the product (wheelchair) on the negative side of the adjectives from the neutral position. In contrast, the responses of the Pakistan group were on the positive side of adjectives scale.

The authors welcome further debate on this topic and collaboration internationally to undertake further comparative studies towards a better understanding of current societal opinions of AT products; and those who use them.

\section{ACKNOWLEDGEMENT:}

The authors gratefully acknowledge the financial support by the University of Engineering and Technology (UET), Lahore and Higher Education Commission (HEC), Pakistan under Faculty Development Program (FDP) scholarship scheme. Thanks also to Prof. Dr. Sabahat Alamgir and colleagues from PID, UET, Lahore, for their continuous support for data collection of participants from the Pakistan. 


\section{Reference}

[1] Business Wire. Disabled \& Elderly Assistive Technologies Market.. [Internet]. East. Daylight Time. 2017 [cited 2017 Dec 20]. Available from: https://bit.ly/2YYOpFc.

[2] WHO. World Report on Disability - Summary. World Rep. Disabil. 2011. 2011;1-23.

[3] Newell AF. Inclusive Design or Assistive Technology. In: Keates S, Lebbon C, Coleman R, et al., editors. Incl. Des. Des. Whole Popul. [Internet]. 2003rd ed. London: Springer Verlag GmbH; 2003. p. 172-181. Available from: http://www.springerlink.com/index/10.1007/978-1-4419-7031-2.

[4] Sun W, Wilson MG, Schreiber D, et al. Ethical challenges related to assistive product access for older adults and adults living with a disability: a scoping review protocol. Syst. Rev. 2017;6:24.

[5] Routhier F, Vincent C, Desrosiers J, et al. Mobility of wheelchair users: a proposed performance assessment framework. Disabil. Rehabil. [Internet]. 2003;25:19-34. Available from: http://www.tandfonline.com/doi/full/10.1080/dre.25.1.19.34.

[6] WHO. Guidelines on the provision of manual wheelchairs in less resourced settings [Internet]. World Heal. Organ. 2008. Available from: http://www.who.int/disabilities/publications/technology/wheelchairguidelines/en/index .html.

[7] WHO. Assistive devices and technologies [Internet]. World Health Organization; 2016 [cited 2017 Aug 3]. Available from: http://www.who.int/disabilities/technology/en/.

[8] Lucintel. Global Wheelchair Market by product, category, design and function, end user, and region 2017-2022 [Internet]. 2017 [cited 2017 Dec 20]. Available from: http://www.lucintel.com/global-wheelchair-market-2017.aspx.

[9] Asghar S, Torrens GE, Harland R. Cross-cultural influences on the semantics ascribed to assistive technology product and its envisaged user. Asian Conf. Media, Commun. Film. MediAsia. [Internet]. Tokyo, Japan.: The International Academic Forum (IAFOR); 2018. p. 263-280. Available from: https://dspace.lboro.ac.uk/2134/36484.

[10] Asghar S, Torrens GE, Harland R. Cultural influences on perception of disability and disabled people: A comparison of opinions from students in the United Kingdom (UK) Pakistan (PAK) about a generic wheelchair using a semantic. Disabil. Rehabil. Assist. Technol. 2019;

[11] Cook AM a., Polgar JM. Assistive Technology: Principles \& Practices [Internet]. 4th ed. Missouri: Elsevier Mosby; 2015. Available from: https://bit.ly/2G39xS0.

[12] Shinohara K, Wobbrock JO. In the shadow of misperception. Proc. 2011 Annu. Conf. Hum. factors Comput. Syst. - CHI '11 [Internet]. 2011. p. 705. Available from: http://dl.acm.org/citation.cfm?doid=1978942.1979044.

[13] Pape TLB, Kim J, Weiner B. The shaping of individual meanings assigned to assistive technology: A review of personal factors. Disabil. Rehabil. 2002;24:5-20.

[14] Kintsch A, Depaula R. A Framework for the Adoption of Assistive Technology. Statew. Assist. Technol. Augment. Altern. Commun. Symp. [Internet]. 2002;1-11. Available from: http://13d.cs.colorado.edu/clever/assets/pdf/ak-SWAAAC02.pdf. 
[15] Parette P, Scherer M. Assistive Technology Use and Stigma. Educ. Train. Dev. Disabil. [Internet]. 2004;39:217-226. Available from: https://bit.ly/2HwIssE.

[16] Stockton G. Stigma : Addressing Negative Associations in Product Design. Int. Conf. Eng. Prod. Des. Educ. 2009. p. 1-6.

[17] Lanutti JNL, Medola FO, Gonçalves DD, et al. The Significance of Manual Wheelchairs: A Comparative Study on Male and Female Users. Procedia Manuf. 2015;3:6079-6085.

[18] Ripat J, Woodgate R. The intersection of culture, disability and assistive technology. Disabil. Rehabil. Assist. Technol. [Internet]. 2011;6:87-96. Available from: http://www.tandfonline.com/doi/full/10.3109/17483107.2010.507859.

[19] Hofstede G. Culture's Consequences. Thousand Oaks: Sage; 2001.

[20] Berry JW, Poortinga YH, Breugelmans SM, et al. Cross-Cultural Psychology. 3rd, editor. Cambridge University Press; 2012.

[21] Matsumoto D, Juang L. Culture and Psychology. 5th ed. Psychol. Akad. Pod. t. 2. Wadsworth Cengage Learning; 2013.

[22] Nisbett RE. The Geography of Thought. NewYork: The Free Press; 2003.

[23] Trembath D, Balandin S, Rossi C. Cross-cultural practice and autism. J. Intellect. Dev. Disabil. 2005;30:240-242.

[24] Krippendorff K. The semantic turn: A new foundation for design [Internet]. Artifact. CRC Press; 2007. Available from: http://scholarworks.iu.edu/journals/index.php/artifact/article/view/1300.

[25] Brown SE. What Is Disability Culture? Disabil. Stud. Q. [Internet]. 2002;22:34-50. Available from: http://dsq-sds.org/article/view/343/433.

[26] Steven E. Brown. “Oh, Don't You Envy Us Our Privileged Lives?” A Review of the Disability Culture Movement. Disabil. Rehabil. 1997;19:339-349.

[27] Bickenbach JE. Disability, culture and the un convention. Disabil. Rehabil. 2009;31:1111-1124.

[28] WHO. Overview of ICF Components. Int. Classif. Funct. Disabil. Heal. 2001.

[29] Hammell KW. Perspectives on Disability and Rehabilitation: Contesting assumptions; challenging practice. Saskatchewan: Elsevier; 2006.

[30] French S, Swain J. Understanding Disability: A Guide for Health Professionals. 2008.

[31] Oliver M. The Politics of Disablement. Leonard P, editor. New York, NY: Palgrave Macmillan; 1990.

[32] Barnes C. Disability and the importance of Design for All. J. Access. Des. All [Internet]. 2011;1:55-80. Available from: https://www.jacces.org/index.php/jacces/article/view/81/148.

[33] Whyte SR, Ingstad B. Disability and Culture: An Overview [Internet]. University of California Press; 1995. p. 3-32. Available from:

http://twren.sites.luc.edu/phil389\&elps423/d\&c.htm. 
[34] Burr V. Social constructionism. New York NY: Routledge; 2003.

[35] Burr V. Social constructionism. 2015.

[36] Whyte SR, Ingstad B. Disability and Culture: An Overview. 1995; Available from: http://twren.sites.luc.edu/phil389\&elps423/d\&c.htm.

[37] Paratte P, Huer MB, Hourcade JJ. Using assistive technology focus groups with families across cultures. Educ. Train. Ment. Retard. Dev. Disabil. 2003;38:429-440.

[38] Markus HR, Kitayama S. Culture and the self: Implications for cognition, emotion, and motivation. Psychol. Rev. 1991;98:224-253.

[39] Masuda T, Nisbett RE. Attending holistically vs. analytically: Comparing the context sensibility of Japanese and American. J. Pers. Soc. Psychol. 2001;81:922-934.

[40] Nisbett RE, Norenzayan A. Culture and Cognition. Stevens' Handb. Exp. Psychol. [Internet]. 3rd ed. John Wiley \& Sons; 2002. Available from: http://wwwpersonal.umich.edu/ nisbett/cultcog2.pdf.

[41] Kastanakis MN, Voyer BG. The effect of culture on perception and cognition: A conceptual framework. J. Bus. Res. [Internet]. 2014;67:425-433. Available from: http://dx.doi.org/10.1016/j.jbusres.2013.03.028.

[42] Goto SG, Ando Y, Huang C, et al. Cultural differences in the visual processing of meaning : Detecting incongruities between background and foreground objects using the N400. Soc. Cogn. Neurosci. 2010;242-253.

[43] Nisbett RE, Choi I, Peng K, et al. Culture and systems of thought: Holistic versus analytic cognition. Psychol. Rev. 2001;108:291-310.

[44] Nisbett RE, Masuda T. Culture and point of view. Biol. Cult. Bases Hum. Inference. 2003;100:11163-11170.

[45] Crilly N. The roles that artefacts play: Technical, social and aesthetic functions. Des. Stud. [Internet]. 2010;31:311-344. Available from: http://dx.doi.org/10.1016/j.destud.2010.04.002.

[46] Crilly N, Moultrie J, Clarkson PJ. Seeing things: Consumer response to the visual domain in product design. Des. Stud. 2004;25:547-577.

[47] Gros J. Sinn-liche Funktionen im Design. Zeitschrift für Gestaltung; 1976. p. 6-9.

[48] Krippendorff K. Klaus Krippendorff or on the Proposition that. Design. 1989;5:9-39.

[49] Giacomin J. What is Design for Meaning? J. Des. Bus. Soc. 2017;3:167-190.

[50] Watson J, Lysonski S, Gillan T, et al. Cultural values and important possessions: A cross-cultural analysis. J. Bus. Res. 2002;55:923-931.

[51] Vaes K. Product Stigmaticity: Understanding, measuring and managing productrelated stigma. Delt, Netherlands; 2014.

[52] Vaes K, Jan P, Standaert A, et al. Measuring Product-Related Stigma in Design. Meas. Prod. Stigma Des. 2016. p. 1-20.

[53] Loughborough University [Internet]. Ethics Approv. (Human Particip. SubCommittee. 2018 [cited 2017 Aug 30]. Available from: 
http://www.lboro.ac.uk/committees/ethics-approvals-human-participants/.

[54] Cohen L, Manion L, Morrison K. Research Methods in Education. Br. J. Educ. Stud. 2007.

[55] Bryman A. Social research methods. 4th ed. Oxford University Press; 2012.

[56] Robson C, McCartan K. Real World Research. 4th ed. London: Wiley; 2016.

[57] Corp I. Survey Monkey. San Mateo, California, USA [Internet]. 2019; Available from: www.surveymonkey.com.

[58] Google L. Google Docs. 2019; Available from: https://docs.google.com/.

[59] Typeform C. Type Form. 2019; Available from: https://www.typeform.com/.

[60] Jisc. Online Survey (BOS). 2019; Available from: https://www.onlinesurveys.ac.uk/.

[61] Malhotra NK. Marketing Research- An Applied Orientation. 6th Editio. Yagan S, editor. Pearson; 2010.

[62] Mangal SK, Mangal S. RESEARCH METHODOLOGY IN BEHAVIOURAL SCIENCES. Edition 1st, editor. PHI Learning; 2013.

[63] Davis M, Jackson R, Smith T, et al. The hearing aid effect in African American and Caucasian males as perceived by female judges of the same race. Lang. Speech Hear. Serv. Sch. 1999;30:165-172.

[64] Lai ML, Tsai MJ, Yang FY, et al. A review of using eye-tracking technology in exploring learning from 2000 to 2012. Educ. Res. Rev. [Internet]. 2013;10:90-115. Available from: http://dx.doi.org/10.1016/j.edurev.2013.10.001.

[65] Tamm M, Prellwitz M. ' If I had a friend in a wheelchair ': children 's thoughts on disabilities. Child Care, Heal. Dev. 2001;27:223-240.

[66] Panek PE, Smith JL. Assessment of terms to describe mental retardation. Res. Dev. Disabil. 2005;26:565-576.

[67] Alcántara E, Artacho MA, González JC, et al. Application of product semantics to footwear design. Part I - Identification of footwear semantic space applying differential semantics. Int. J. Ind. Ergon. 2005;35:713-725.

[68] Ahlborn LJ, Panek PE, Jungers MK. College students' perceptions of persons with intellectual disability at three different ages. Res. Dev. Disabil. 2008;29:61-69.

[69] Fellinghauer BAG, Roth A, Bugari K, et al. Construct Validity, Test-Retest Reliability, and Internal Consistency of the Photo Elicitation Semantic Differential Scale (PESD) in Disability Studies. J. Dev. Phys. Disabil. 2011;23:257-265.

[70] Elliott AC, Woodward WA. Statistical Analsis Quick Reference Guidebook: with SPSS Examples. Thousand Oaks, California: SAGE Publications, Inc.; 2007.

[71] Coşkunserçe O. Microsoft Excel 2016. Bilgi. giriş. 2017.

[72] Corp I. IBM SPSS Statistics for Windows. New York IBM Corp. 2015;

[73] Mallan K. Author-illustrator. Routledge Companion to Pict. 2018.

[74] Asghar S. Figshare [Internet]. Dataset_Influ. Soc. Context Percept. Assist. Technol. 
Using a Semant. Differ. scale to Comp. young adults' views from UK Pakistan. 2019. Available from: https://repository.lboro.ac.uk/s/28da77e6ebddf2c850df\%0A.

[75] Hall ET. Beyond Culture [Internet]. 2nd, editor. Anchor Books; 1989. Available from: https://monoskop.org/images/6/60/Hall_Edward_T_Beyond_Culture.pdf.

[76] Gooberman-Hill R, Ebrahim S. Making decisions about simple interventions: Older people's use of walking aids. Age Ageing. 2007;36:569-573.

[77] Shinohara K, Wobbrock JO. In the shadow of misperception. Proc. 2011 Annu. Conf. Hum. factors Comput. Syst. - CHI '11 [Internet]. 2011;705. Available from: http://dl.acm.org/citation.cfm?doid=1978942.1979044.

[78] Moalosi R, Popovic V, Hickling-Hudson A. Culture-orientated product design. Int. J. Technol. Des. Educ. 2010. p. 175-190.

[79] Lu W, Čok V, Zhu R. Study on Cultural Differences of Users' Perception towards Shape Characteristics. 2014;1135-1146.

[80] Lesot M-J, Bouchard C, Detyniecki M, et al. Product Shape and Emotional Design an Application To Perfume Bottles. Int. Conf. Kansei Eng. Emot. Res. 2010. Paric; 2010.

[81] Chan Cheng Yee B, Yazdanifard R, Cheng Yee $\alpha$ C, et al. How Customer Perception Shape buying Online Decision. Glob. J. Manag. Bus. Res. 2014;14.

[82] Osgood CE, Suci GJ, Tannenbaum PH. The measurement of meaning. 2nd ed. Urbana, Chicago and London: University of Illinois Press; 1957.

[83] Osgood CE. Semantic Differential Technique in the Comparative Study of Cultures. Am. Anthropol. 1964;66:171-200.

[84] Petiot JF, Yannou B. Measuring consumer perceptions for a better comprehension, specification and assessment of product semantics. Int. J. Ind. Ergon. 2004;33:507525 .

[85] Artacho-Ramirez MA, Diego-Mas JA, Alcaide-Marzal J. Influence of the mode of graphical representation on the perception of product aesthetic and emotional features: An exploratory study. Int. J. Ind. Ergon. 2008;38:942-952.

[86] Moon H, Park J, Kim S. The importance of an innovative product design on customer behavior: Development and validation of a scale. J. Prod. Innov. Manag. 2015;32:224232. 


\begin{tabular}{|l|l|l|l|l|l|l|l|l|}
\hline & 1 & 2 & 3 & 4 & 5 & 6 & 7 & \\
\hline Weak & & & & & & & & Strong \\
\hline
\end{tabular}

Example of SD scale used in the pilot study.

\begin{tabular}{|c|c|c|c|c|c|c|c|c|}
\hline & $\begin{array}{l}\text { Strongly } \\
\text { Aligned 1 }\end{array}$ & $\mathbf{2}$ & $\mathbf{3}$ & Neutral 4 & $\mathbf{5}$ & $\mathbf{6}$ & $\begin{array}{l}\text { Strongly } \\
\text { Aligned 7 }\end{array}$ & \\
\hline Weak & $\square$ & $\square$ & $\square$ & $\square$ & $\square$ & $\square$ & $\square$ & Strong \\
\hline
\end{tabular}

Example of SD scale used in the study 01.

Figure 01: Transition from earlier (upper) to revised (lower) SD scale 


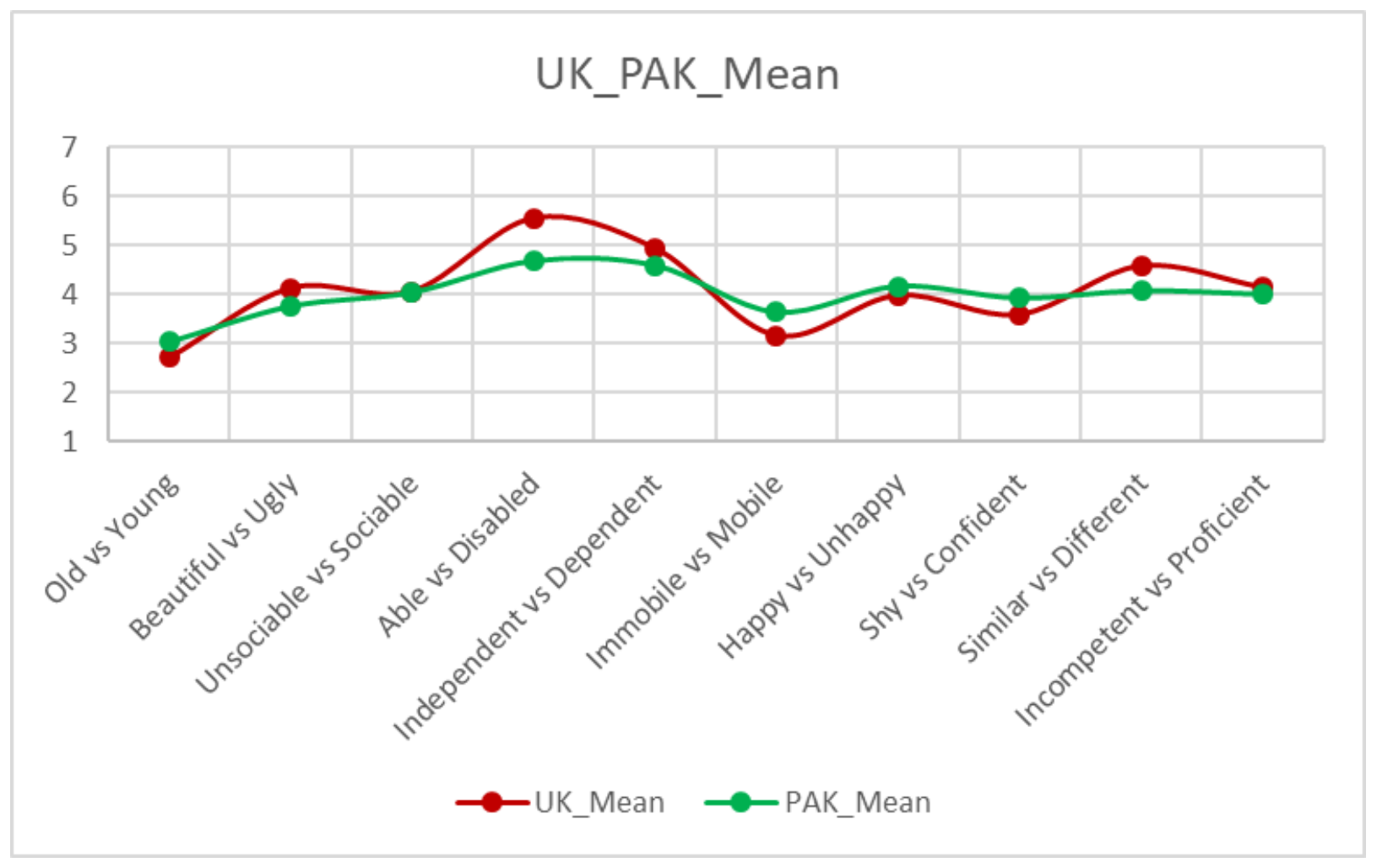

Figure 02: Comparing the $\mathrm{M}$ values of both groups (SD scale for envisaged user) 


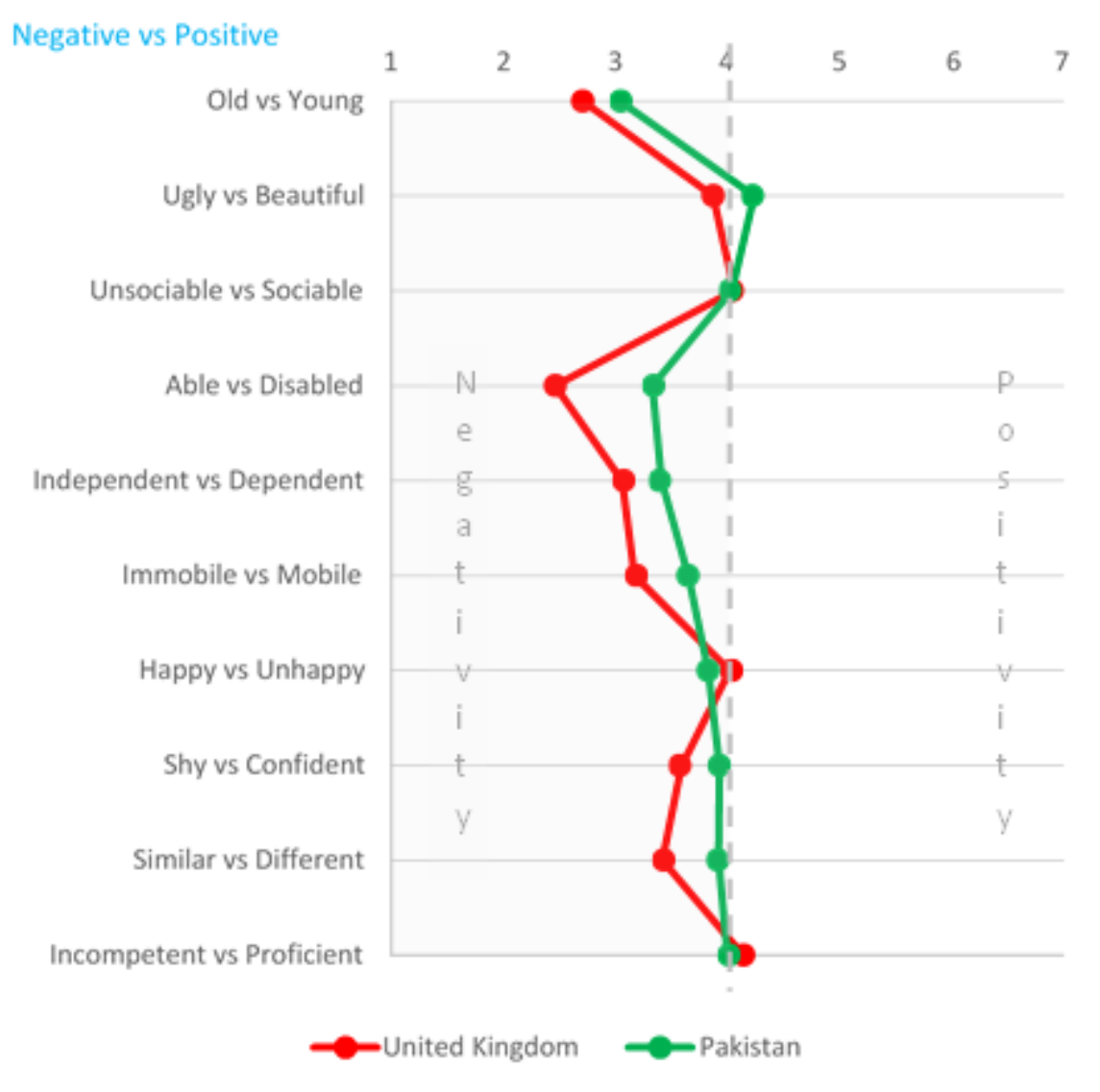

Figure 03: Associated 'Negativity' and 'Positivity' with the envisage user 


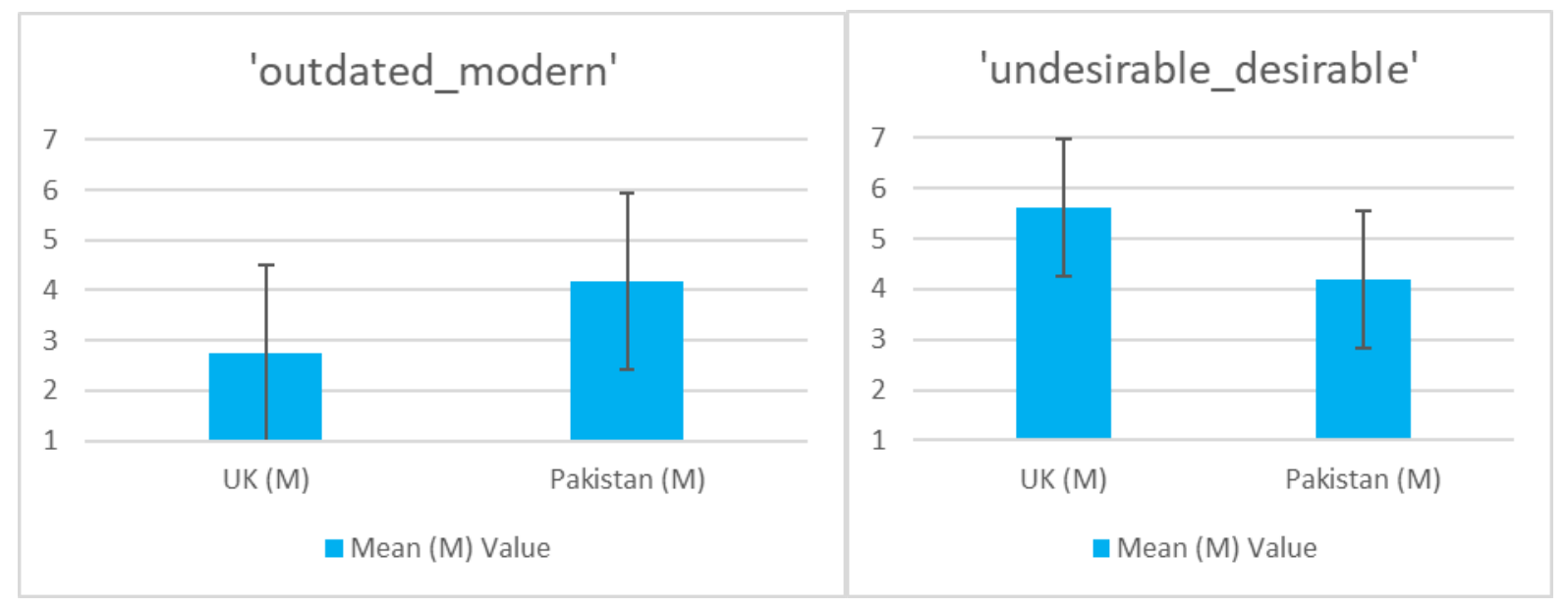

Figure 04: Comparison of the UK and Pakistan, $M$ values towards semantic attributed to the product 


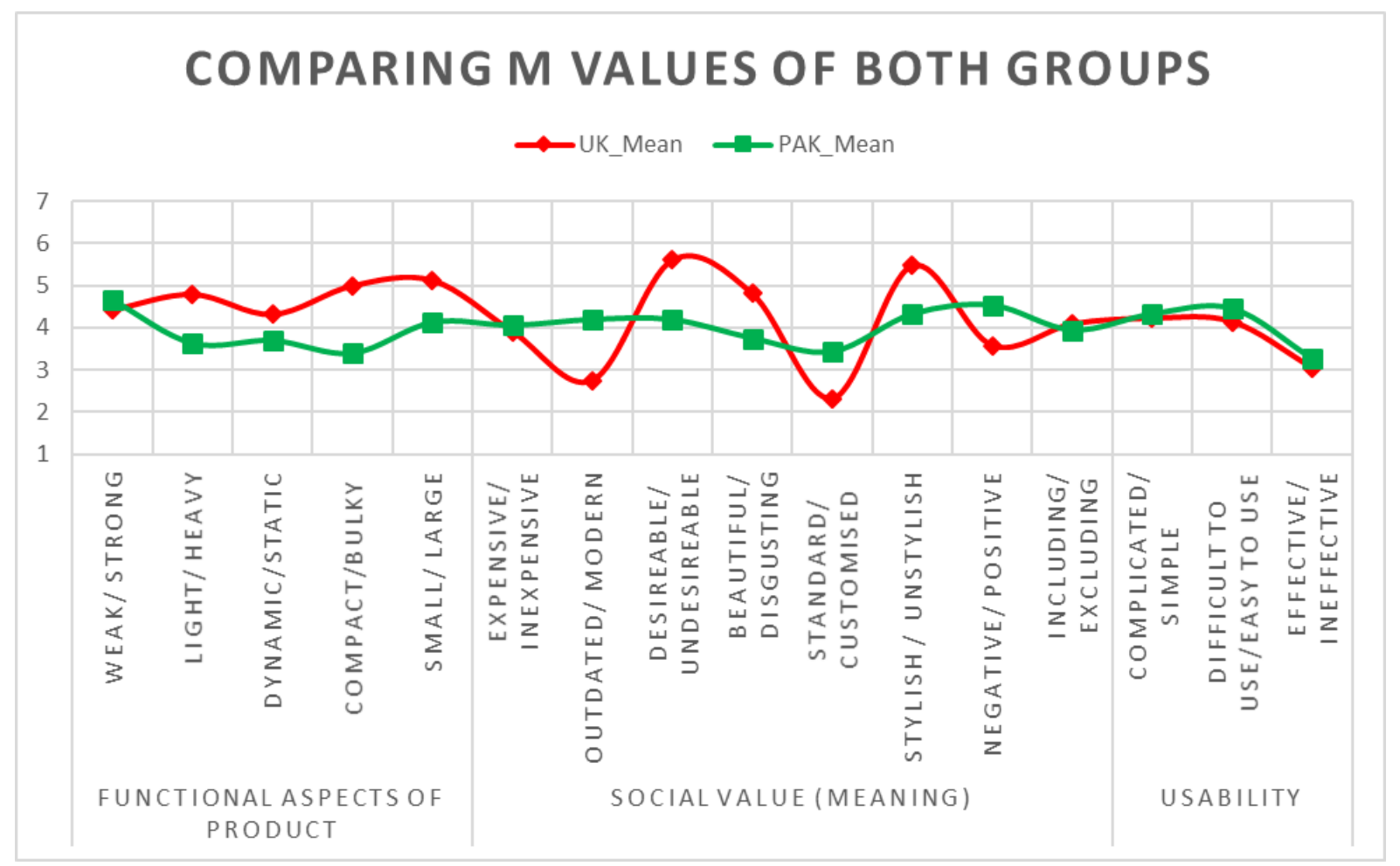

Figure 05: Comparing the $\mathrm{M}$ values of both groups for all pairs of adjectives 


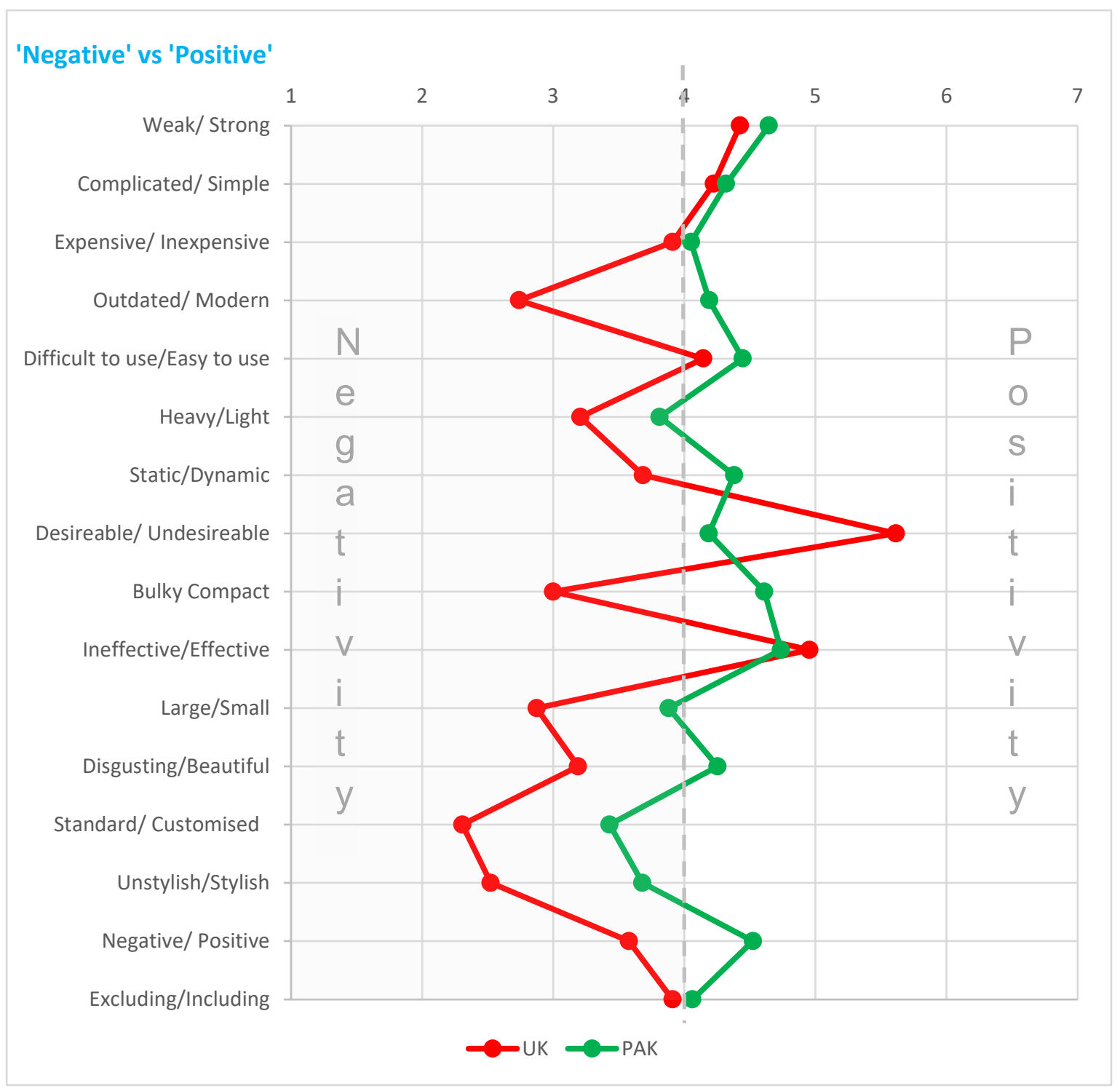

Figure 06: Comparison of associated 'Negativity' and 'Positivity' with the product 


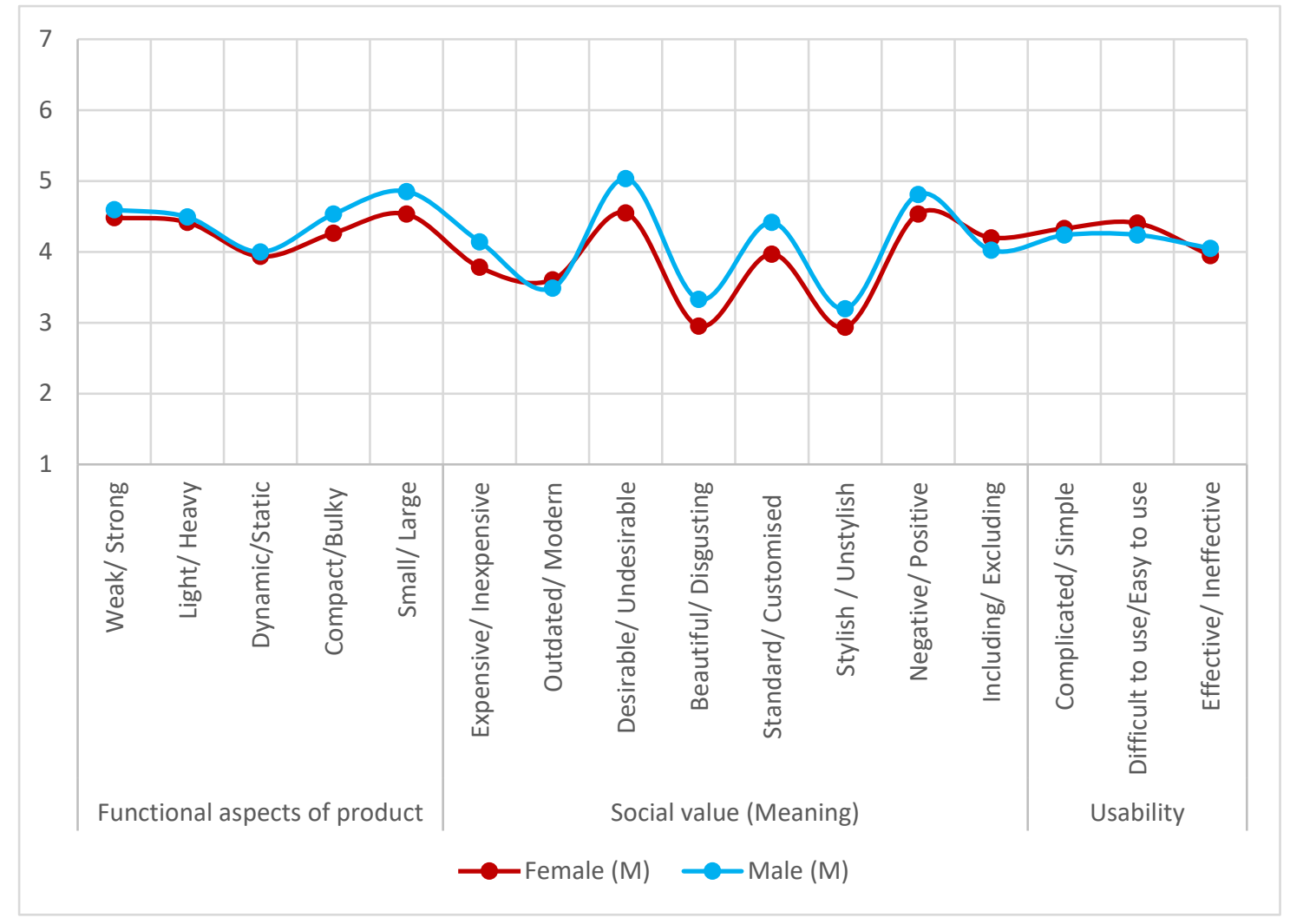

Figure 07: Comparison of responses $M$ values based on gender 


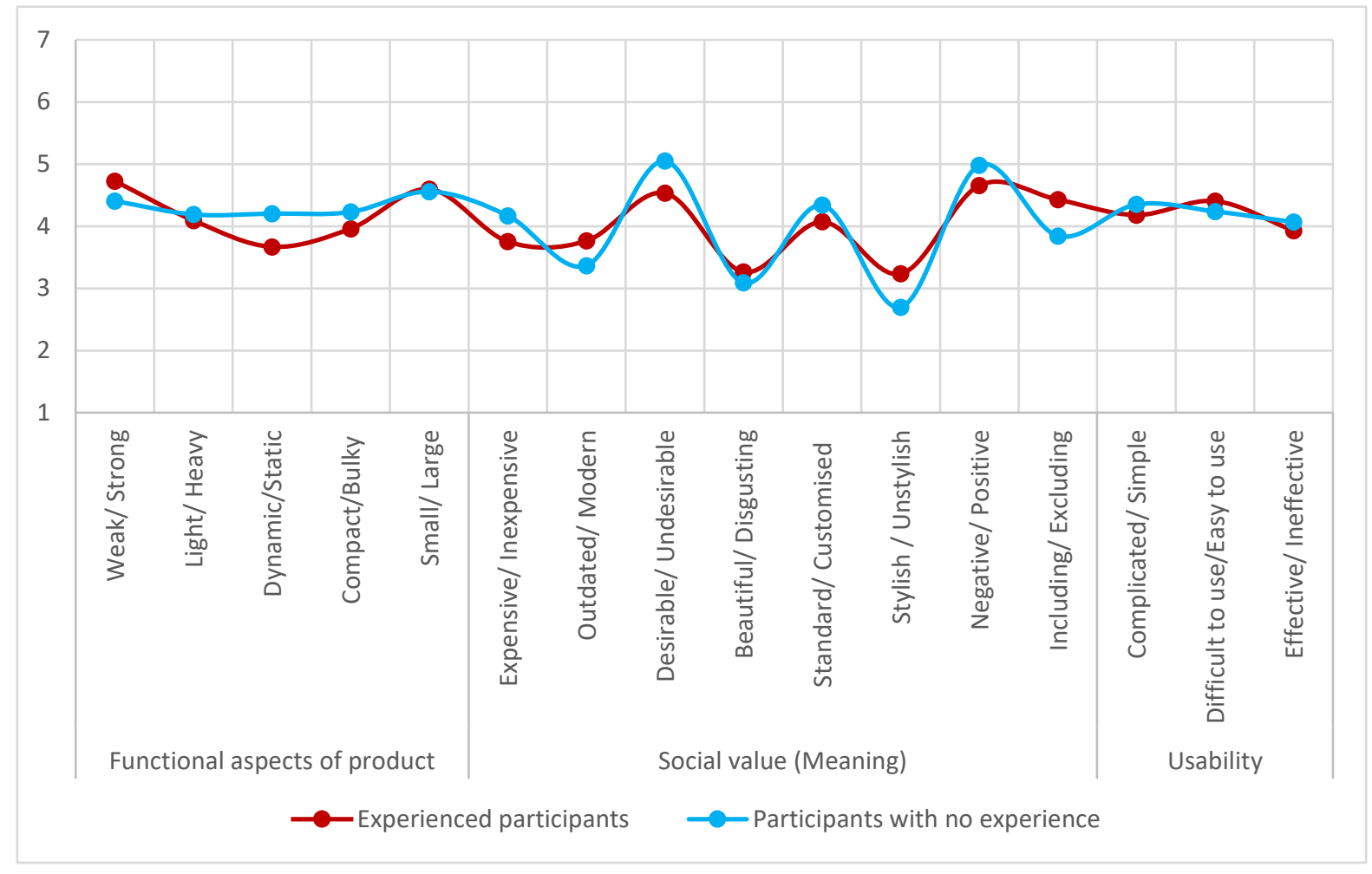

Figure 08: Comparison of responses having previous experience of using wheelchair and those without any experience 
Table 1: Summary of basic and demographic profile of respondents

\begin{tabular}{|c|c|c|}
\hline Basic Information & United Kingdom & Pakistan \\
\hline Total participants & $444(44.8 \%)$ & $547(55.2 \%)$ \\
\hline Male & $244(55 \%)$ & $320(58.5 \%)$ \\
\hline Female & $200(45 \%)$ & $227(41.5 \%)$ \\
\hline Age limit & 18 to 30 & 18 to 30 \\
\hline \multicolumn{3}{|c|}{ Participants demographic Information } \\
\hline & England & Punjab \\
\hline $\begin{array}{l}\text { Participants (with } \\
\text { practicing religion) }\end{array}$ & $\begin{array}{l}320(72.1 \%) \\
\left(313 \_C h r i s t i a n, 06 \_ \text {Islam, }\right. \\
01 \text { other) }\end{array}$ & $\begin{array}{l}521(95.2 \%) \\
\text { (518_Islam, 03_Christian) }\end{array}$ \\
\hline $\begin{array}{l}\text { Participants (with no } \\
\text { religion) }\end{array}$ & $124(27.9 \%)$ & $26(4.8 \%)$ \\
\hline
\end{tabular}


Table 02: Participants with past experience of interaction with product

\begin{tabular}{|l|l|l|l|l|}
\cline { 2 - 5 } \multicolumn{1}{c|}{} & \multicolumn{2}{l|}{ United Kingdom } & Pakistan \\
\cline { 2 - 5 } \multicolumn{1}{c|}{} & Yes & No & Yes & No \\
\hline Ever used wheelchair & 24 & 420 & 41 & 506 \\
\hline Helped wheelchair user & 80 & 364 & 266 & 281 \\
\hline Know any wheelchair user & 64 & 380 & 129 & 418 \\
\hline
\end{tabular}


Table 03: Group descriptive statistics for first SD scale

\begin{tabular}{|c|c|c|c|c|c|c|c|c|c|c|c|}
\hline \multicolumn{2}{|c|}{$\begin{array}{c}\text { SD scale for } \\
\text { envisaged user } \\
\text { of the } \\
\text { wheelchair }\end{array}$} & $\begin{array}{r}\text { Old vs } \\
\text { Young } \\
1 \\
\end{array}$ & $\begin{array}{r}\begin{array}{l}\text { Beautiful } \\
\text { vs Ugly }\end{array} \\
1 \\
\end{array}$ & $\begin{array}{r}\text { Unsociable } \\
\text { vs Sociable } \\
2 \\
\end{array}$ & $\begin{array}{r}\begin{array}{c}\text { Able vs } \\
\text { Disabled }\end{array} \\
1 \\
\end{array}$ & $\begin{array}{l}\begin{array}{c}\text { Independent } \\
\text { vs } \\
\text { Dependent }\end{array} \\
1 \\
\end{array}$ & $\begin{array}{r}\begin{array}{c}\text { Immobile } \\
\text { vs } \\
\text { Mobile }\end{array} \\
1 \\
\end{array}$ & $\begin{array}{r}\text { Happy vs } \\
\text { Unhappy } \\
1 \\
\end{array}$ & $\begin{array}{r}\begin{array}{c}\text { Shy vs } \\
\text { Confident }\end{array} \\
1 \\
\end{array}$ & $\begin{array}{r}\begin{array}{c}\text { Similar } \\
\text { vs } \\
\text { Different }\end{array} \\
1\end{array}$ & $\begin{array}{l}\text { Incompeten } \\
\text { vs Proficient }\end{array}$ \\
\hline \multirow{3}{*}{$U K$} & Maximum & 7 & 7 & 7 & 7 & 7 & 7 & 7 & 6 & 7 & 7 \\
\hline & Mean & 2.71 & 4.13 & 4.06 & 5.54 & 4.94 & 3.17 & 3.98 & 3.59 & 4.58 & 4.14 \\
\hline & Mode & 2 & 4 & 4 & 6 & 6 & 2 & 4 & 4 & 5 & 3 \\
\hline \multirow{4}{*}{ PAK } & Minimum & 1 & 1 & 1 & 1 & 1 & 1 & 1 & 1 & 1 & 1 \\
\hline & Maximum & 7 & 7 & 7 & 7 & 7 & 7 & 7 & 7 & 7 & 7 \\
\hline & Mean & 3.04 & 3.76 & 4.04 & 4.67 & 4.59 & 3.65 & 4.17 & 3.93 & 4.08 & 4.00 \\
\hline & $S D$ & 1.92 & 1.66 & 1.77 & 2.16 & 2.07 & 2.03 & 1.91 & 1.85 & 1.72 & 1.74 \\
\hline
\end{tabular}


Table 04: $\mathrm{P}$ values from independent $\mathrm{t}$-sample test

\section{Independent Samples Test}

\begin{tabular}{lr|r|} 
& T value & Sig. / p-value \\
\hline Old_Young & -3.182 & .002 \\
\hline Beautiful_Ugly & 3.801 & .000 \\
\hline Unsociable_sociable & .232 & .817 \\
\hline Able_Disabled & 7.185 & .000 \\
\hline Independent_Dependent & 3.092 & .002 \\
\hline Immobile_Mobile & -4.093 & .000 \\
\hline Happy_Unhappy & -1.717 & .086 \\
\hline Shy_Confident & -3.296 & .001 \\
\hline Similar_Different & 4.826 & .000 \\
\hline Incompetent_Proficient & 1.439 & .138 \\
\hline
\end{tabular}


Table 05: Group descriptive statistics for SD scale indicating semantics of the product

\begin{tabular}{|c|c|c|c|c|c|c|c|c|c|c|c|c|c|c|c|c|c|}
\hline \multicolumn{2}{|c|}{$\begin{array}{l}\text { SD scale for } \\
\text { semantics of } \\
\text { the wheelchair }\end{array}$} & 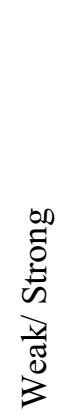 & 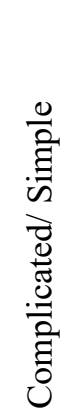 & 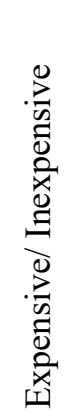 & 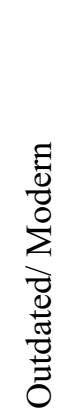 & 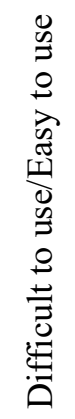 & 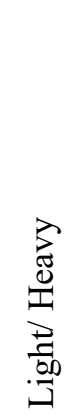 & 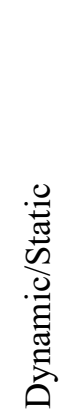 & 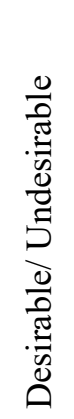 & 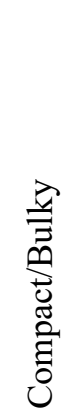 & 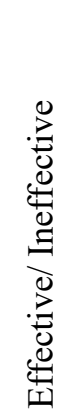 & 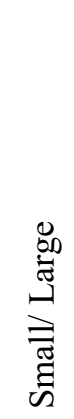 & 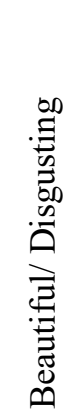 & 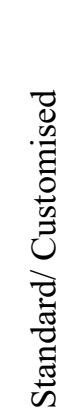 & 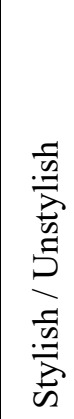 & 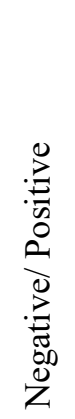 & 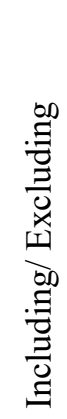 \\
\hline \multirow{6}{*}{ UK } & Minimum & 1 & 1 & 1 & 1 & 1 & 2 & 1 & 1 & 1 & 1 & 3 & 1 & 1 & 1 & 1 & 1 \\
\hline & Maximum & 7 & 7 & 7 & 7 & 7 & 7 & 7 & 7 & 7 & 6 & 7 & 7 & 6 & 7 & 7 & 7 \\
\hline & Mean & 4.42 & 4.23 & 3.91 & 2.74 & 4.14 & 4.79 & 4.32 & 5.61 & 5.00 & 3.05 & 5.13 & 4.81 & 2.31 & 5.48 & 3.58 & 4.09 \\
\hline & $S D$ & 1.55 & 1.44 & 1.41 & 1.46 & 1.66 & 1.38 & 1.45 & 1.35 & 1.47 & 1.40 & 1.01 & 1.13 & 1.41 & 1.20 & 1.38 & 1.46 \\
\hline & Median & 4 & 4 & 4 & 3 & 4 & 5 & 4 & 6 & 5 & 3 & 5 & 5 & 2 & 6 & 3 & 4 \\
\hline & Mode & 3 & 5 & 4 & 2 & 4 & 5 & 4 & 6 & 6 & 2 & 5 & 5 & 1 & 6 & 4 & 4 \\
\hline \multirow{6}{*}{ PAK } & Minimum & 1 & 1 & 1 & 1 & 1 & 1 & 1 & 1 & 1 & 1 & 1 & 1 & 1 & 1 & 1 & 1 \\
\hline & Maximum & 7 & 7 & 7 & 7 & 7 & 7 & 7 & 7 & 7 & 7 & 7 & 7 & 7 & 7 & 7 & 7 \\
\hline & Mean & 4.65 & 4.32 & 4.05 & 4.19 & 4.45 & 3.62 & 3.69 & 4.19 & 3.39 & 3.26 & 4.12 & 3.75 & 3.43 & 4.32 & 4.52 & 3.94 \\
\hline & $S D$ & 2.08 & 2.06 & 1.90 & 1.76 & 1.99 & 2.24 & 1.67 & 1.88 & 2.10 & 1.76 & 1.89 & 1.59 & 1.89 & 1.87 & 1.65 & 1.56 \\
\hline & Median & 4 & 4 & 4 & 4 & 4 & 2 & 4 & 4 & 2 & 3 & 3 & 4 & 3 & 5 & 4 & 4 \\
\hline & & 7 & 4 & 4 & 4 & 7 & 2 & 4 & 4 & 2 & 4 & 3 & 4 & 3 & 5 & 4 & 4 \\
\hline
\end{tabular}


Table 06: Descriptive statistics for participants with experience and those with no experience

\begin{tabular}{|l|c|c|c|c|}
\hline \multicolumn{1}{|c|}{$\begin{array}{c}\text { Pair of } \\
\text { adjectives }\end{array}$} & \multicolumn{2}{c|}{$\begin{array}{c}\text { Response from having previous } \\
\text { experience of using wheelchair }\end{array}$} & \multicolumn{2}{c|}{$\begin{array}{c}\text { Response from having no previous } \\
\text { experience of using wheelchair }\end{array}$} \\
\hline & Mean (M) & SD & Mean (M) & SD \\
\hline Dynamic/Static & 3.67 & 1.68 & 4.20 & 1.51 \\
\hline Compact/Bulky & 3.96 & 2.16 & 4.23 & 1.88 \\
\hline $\begin{array}{l}\text { Expensive/ } \\
\text { Inexpensive }\end{array}$ & 3.75 & 1.80 & 4.17 & 1.59 \\
\hline $\begin{array}{l}\text { Desirable/ } \\
\text { Undesirable }\end{array}$ & 4.53 & 1.90 & 5.05 & 1.63 \\
\hline $\begin{array}{l}\text { Stylish / } \\
\text { Unstylish }\end{array}$ & 3.23 & 1.79 & 2.70 & 1.45 \\
\hline $\begin{array}{l}\text { Including/ } \\
\text { Excluding }\end{array}$ & 4.43 & 1.60 & 3.84 & 1.52 \\
\hline $\begin{array}{l}\text { Effective/ } \\
\text { Ineffective }\end{array}$ & 3.93 & 1.72 & 4.07 & \\
\hline
\end{tabular}

